\title{
РЫБОХОЗЯЙСТВЕННОЕ ОБРАЗОВАНИЕ
}

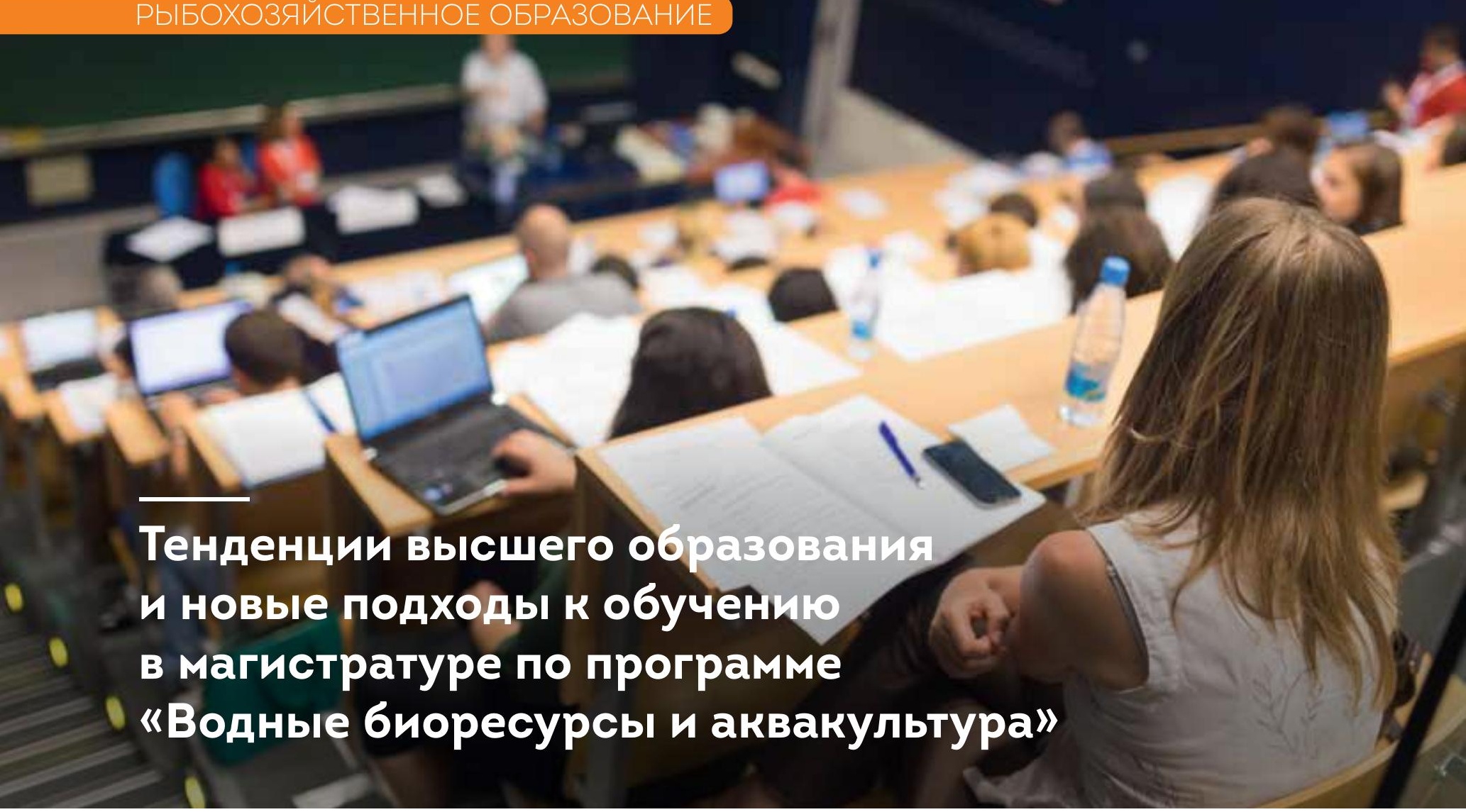

Д-р экон. наук, профессор М.В. Шатохин;

канд. биол. наук, профессор А.К. Пономарев;

аспирант О.В. Горбунов;

д-р биол. наук профессор

А.Л. Никифоров-Никишин -

Московский государственный университет технологий

и управления им. К.Г.

Разумовского (ПКУ)

@shato-hinm@mail.ru; ponomarev777@inbox.ru; akvabiotex@rambler.ru; 9150699@mail.ru

Ключевые слова:

профессиональное образование, учебный процесс, умения и навыки, технологии, водные биоресурсы, аквакультура

Keywords:

vocational education, educational process, skills, technologies, aquatic bioresources, aquaculture

TRENDS IN HIGHER EDUCATION

AND NEW APPROACHES TO MASTER'S STUDIES

IN THE MASTER'S PROGRAM “AQUATIC BIORESOURCES AND AQUACULTURE”

Shatokhin M.V., Doctor of Sciences, Professor, Ponomarev A.K., PhD, Professor, Gorbunov O.V. postgraduate, Nikiforov-Nikishin A.L., Doctor of Sciences, Professor - Moscow State University of Technologies and Management, shato-hinm@mail.ru; ponomarev777@inbox.ru akvabiotex@rambler.ru; 9150699@mail.ru

The article discusses the current trends in the higher education development. The new approach to the organization of the educational process is needed to develop and form the professional competencies of students. In particular, the use of modern educational technologies, interactive teaching methods in the training process organization. The use of these teaching methods allows students to get a high-paying job and be in demand in the labor market in the future.

This is because specialists receive in-depth knowledge on water bodies' creation under any conditions - from a desert to highlands; usage of special vehicles for fish catching and breeding; managing technological processes; evaluation of the biological parameters of products; environmental testing and determining water bodies' suitability for fish and crustaceans breeding. Students must undergo an internship that allows them to apply their knowledge and skills in their work.

Развитие рыбного хозяйства создало повышенный спрос на квалифицированные кадры. Одним из самых главных направлений в экономике развитых стран в современном мире стало развитие аквакультуры, что позволяет не только не нарушить естественного баланса в морях и реках, но и контролировать процесс разведения рыбы. Магистерская программа «Водные биоресурсы» направлена на подготовку грамотных специалистов, которые в будущем смогут способствовать снабжению страны экологически чистыми отечественными продуктами. Для этого понадобится в несколько раз увеличить объемы разведения и вылова рыбы, решить вопрос выращивания ракообразных, наладить товарное производство. Эти и 
другие проблемы углубленно изучаются на данной специальности.

По предварительным данным Росстата, за 2018 г. объем производства переработанной и консервированной рыбы, ракообразных и моллюсков увеличился на 3,05\% и составил 4164 тыс. тонн.

В современных условиях становится очевидным тот факт, что рыбоводство и рыболовство перспективная отрасль, корни которой уходят глубоко в историю.

Современное общество нуждается в специалистах, обладающих такими качествами как самостоятельность, мобильность, творческое мышление. Это подчеркнуто в Концепции долгосрочного социально-экономического развития: «Возрастание роли человеческого капитала является одним из основных факторов экономического развития» [1]. В современном информационном и образовательном пространстве эта задача не может быть решена без использования новых технологий. Таким образом, высшее образование направлено на повышение компетентности в формировании новой культуры мышления [2]. Невозможно достичь этой цели без учета личности преподавателя, его мировоззрения, способности убеждать и нести определенные творческие идеи.

Выбор в обучении дисциплине по водным биоресурсам преподаватели делают в пользу смешанных технологий - сочетание традиционного обучения и инновационного подхода к процессу обучения [3].

Использование информационно-коммуникационных технологий позволяет обеспечить преемственность социокультурного опыта и формирование творческого и критического мышления студентов.

Образовательная программа магистратуры по направлению подготовки «Водные биоресурсы» представляет собой комплекс основных характеристик образования, разработанный с учетом требований рынка труда и развития науки, культуры, экономики, техники, технологий и социальной сферы.

Магистерская программа регламентирует цели, ожидаемые результаты, содержание, организационно-педагогические условия и технологии реализации образовательного процесса, формы аттестации, оценку качества подготовки выпускника по данному направлению и включает в себя: учебный план, календарный учебный

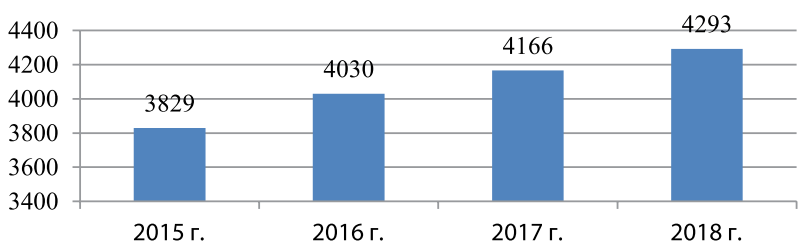

Рисунок 1. Производство рыбной продукции в 2015-2018 гг. (тыс. тонн)

Figure 1. Manufacturing of fish products in 2015-2018 (thousand tons)
В статье рассматриваются современные тенденции развития высшего образования, которые применяются по программе магистратуры «Водные биоресурсы». Новый подход к организации учебного процесса, с целью развития и формирования профессиональных компетенций учащихся, в высшей школе требуется для использования интерактивных методов и организации процесса обучения магистров. Все это позволяет студентам в будущем устроиться на высокооплачиваемую работу и быть востребованными на рынке труда.

Будущие специалисты получают углубленные знания в сфере создания водных объектов в любых условиях - от пустыни до высокогорья; в использовании спецмашин для вылова и разведения рыбы; в управлении технологическими процессами; учатся оценивать биологические параметры продукции, окружающую среду, умению определять пригодность водоемов для разведения рыбы и ракообразных. Студенты в обязательном порядке проходят практику, которая позволяет применить полученные знания и умения в работе.

график, рабочие программы дисциплин (модулей), программы практик, средства в виде фонда оценочных средств для текущей и промежуточной аттестации обучающихся и для государственной итоговой аттестации, методов и средств обучения, применяемых образовательных технологий и учебно-методического обеспечения реализации $\mathrm{OП} \mathrm{BO.}$

Магистерская программа по направлению подготовки «Водные биоресурсы» способствует развитию у студентов личностных качеств, а также формирование общекультурных, универсальных (общенаучных, социально-личностных, инструментальных), общепрофессиональных и профессиональных компетенций в соответствии с требованиями ФГОС ВО. Это позволит готовить высококвалифицированные кадры, руководящий персонал и специалистов для Центрального Управления по рыбохозяйственной экспертизе и нормативам по сохранению, воспроизводству водных биологических ресурсов и акклиматизации.

Современные тенденции развития высшего образования требуют нового подхода к организации образовательного процесса с целью развития и формирования профессиональных компетенций студентов. Сущность государственного социального заказа в Российской Федерации отражена в ФГОС, как требование к уровню профессионального образования выпускника по направлению образовательной программы.

Для реализации ООП, магистратуры на базе ФГОС используют интерактивные и активные формы ведения учебного процесса, составляющего не менее 20\%.

Обучение должно способствовать приобретению опыта и навыков, которые используются в области научных исследований и практической деятельности. В системе высшего образования, при реализации учебного плана, широко представлены различные, личностно-педагогические технологии: информационные и коммуникацион- 
ные (мультимедиа, интерактивные курсы), активное, эвристическое, проблемное, дополнительное образование, кооперативная педагогика и т.д. [4].

Развитие профессиональных компетенций и личностных качеств напрямую зависит от методов и техник, используемых преподавателем в соответствии с целями, выбранными учебными пособиями и используемыми технологиями.

Современное образование в институте невозможно представить без мультимедийных технологий. Мультимедийные занятия дают учащимся возможность воспринимать учебные материалы, развивают способность синтезировать, анализировать, сравнивать, четко организовывать самостоятельную и групповую работу и активировать творческую деятельность. Например, использование презентаций в изучении дисциплин предоставляет студентам более полную и достоверную информацию о процессе, повышает роль наглядности и экономит время на учебе, нежели при конспектировании сложного малознакомого материала.

Использование такого подхода позволяет повысить интерес студентов к изучаемой дисциплине и эффективности учебного процесса, а также глубже понять необходимый материал. Вторым по популярности интерактивным методом преподавания дисциплины является творческая работа по заданию, предложенному преподавателем, которая требует проявления воображения, а не только воспроизведения информации. Эти задания содержат элемент новизны. Для их выполнения необходимо найти собственное «правильное» решение, с точки зрения учащегося, основываясь на собственном опыте и опыте коллег [5].

Важной особенностью современного образования является его постоянное совершенствование. Переход на стандарты нового поколения в образовательном процессе университета является насущной необходимостью использования современных образовательных технологий. Научно-технический прогресс, компьютеризация общества требуют от студентов овладения особыми характеристиками современного образовательного процесса. Рынок труда нуждается в профессионалах, которые способны анализировать проблемы и ситуации, возникающие в их деятельности, предлагать решения этих проблем. Образование способствует формированию многогранной личности, способной к самоанализу, самооценке и уверенности в себе. Поэтому необходимо использовать такие методы обучения, которые направлены на развитие творческих, коммуникативных и аналитических навыков, а также углубляют учебный процесс, делая его более продуктивным и интересным для студентов.

Использование современных методов обучения формирует правильные профессиональные навыки, обеспечивает подготовку специалиста, способного грамотно мыслить и принимать оптимальные решения, помогает решать задачи обучения с высокой эффективностью. Эти методы могут быть использованы в различных образовательных программах.

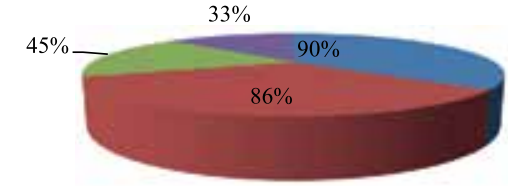

- Переработка рыбы и морепродуктов

- Рыболовство и добыча морепродуктов

Рисунок 2. Востребованность специалистов на рынке труда по видам деятельности до 2030 года, \%

Figure 2. Demand for specialists in the labor market by type of activity until 2030 in percent

При изучении экологических дисциплин можно применять игровые технологии и кооперативную педагогику, которые способствуют расширению горизонта, развитию познавательной деятельности и созданию определенных навыков и умений, необходимых в практической деятельности.

\section{ЛИТЕРАТУРА И ИСТОЧНИКИ}

1. Распоряжение Правительства Российской Федерации от 14 ноября 2008 г. $\mathrm{N}^{\circ} 1662$-р «Концепция долгосрочного социально-экономического развития РФ на период до 2020 г.» - Электронный ресурс. - Режим доступа из URL; http://www. consultant.ru/document/cons_ doc_LAW_82134/ (дата обращения; 22.03.2019)

1. Rasporyazhenie Pravitel'stva Rossijskoj Federacii ot 14 noyabrya 2008 g. No 1662-r «Koncepciya dolgosrochnogo social'no-ekonomicheskogo razvitiya RF na period do 2020 g.» - Web resource. - URL; http://www. consultant.ru/document/cons doc LAW 82134/

2. Распоряжение Правительства Российской Федерации от 29 декабря 2014 г. № 2765-р «Концепция Федеральной целевой программы образования на 2016-2020 годы». - Электронный ресурс. Режим доступа из URL: http://government.ru/media/files/mlorkfxbbck.pdf (дата обращения: 10.04.2019)

2. Rasporyazhenie Pravitel'stva Rossijskoj Federacii ot 29 dekabrya 2014 g. № 2765-r «Koncepciya Federal'noj celevoj programmy obrazovaniya na 2016-2020 gody». - Web resource. URL: http://government.ru/ media/files/mlorkfxbbck.pdf

3. Бейсекова Р.Т., Омарова Г.А., Мунашова Ж.Б. Новейшие социальные технологии в преподавании социально-гуманитарных дисциплин в высшей школе // Социосфера. - 2016. - № 3. C. 207-210;

3. Bejsekova R.T., Omarova G.A., Munashova ZH.B. Novejshie social'nye tekhnologii v prepodavanii social'no-gumanitarnyh disciplin $\mathrm{v}$ vysshej shkole // Sociosfera. - 2016. - № 3. S. 207-210;

4. Алексеенко О.Н. Использование интерактивных методов на профильно-ориентированных занятиях по иностранному языку // Алексеенко O. H. - Электронный ресурс - Режим доступа из URL: http://festival.1september.ru/ articles/607308/ (дата обращения: 02.05.2019)

4. Alekseenko O.N. Ispol'zovanie interaktivnyh metodov na profil'noorientirovannyh zanyatiyah po inostrannomu yazyku // Alekseenko O. N. - Web resource - URL: http://festival.1september.ru/ articles/607308,

5. Двуличанская Н.Н. Интерактивные методы обучения как средство формирования ключевых компетентностей // Электронное научнотехническое издание «Наука и образование». № 9. 2017 г. - [Электронный ресурс]. - Режим доступа из URL: http://technomag.edu.ru/ doc/172651.html (дата обращения: 18.03.2019)

5. Dvulichanskaya N.N. Interaktivnye metody obucheniya kak sredstvo formirovaniya klyuchevyh kompetentnostej // Elektronnoe nauchnotekhnicheskoe izdanie «Nauka i obrazovanie». № 9. 2017 g. - [Web resource]. - URL: http://technomag.edu.ru/doc/172651.html 